\title{
Role expectation and role performance of lady supervisors under ICDS
}

\author{
RUNI KUMARI*, MEERA SINGH AND A.K. PASWAN ${ }^{1}$ \\ Department of Home Science Extension and Communication Management, College of Home Science, \\ Dr. Rajendra Prasad Central Agricultural University, Pusa, SAMASTIPUR (BIHAR) INDIA. \\ ${ }^{1}$ Department of Extension Education, Tirhut College of Agriculture, Dholi, MUZAFFARPUR (BIHAR) INDIA
}

\begin{abstract}
The present research enterprises were carryout Samastipur district of north Bihar region to assessment of role expectation and role performance of lady supervisor under the ICDS. The research aims at assessing the role performance against their expected role of lady supervisors. The Supervisor is the immediate senior official of the Anganwadi workers and subordinate to the Child Development Project Officer. Lady supervisors are the key person for implementation of this programme at ground level. The findings shows that majority of the respondents (68.97\%) had reported their role expectation high level followed by 29.31 per cent and only 1.72 per cent respondent had reported their role expectation medium and low level, respectively. Further findings reveals that a maximum 62.07 per cent of the lady supervisors have high level of the role performance followed by 36.21 per cent and 1.72 per cent lady supervisors have their role performance medium and low level, respectively. Percentage intensity of the gap in the roles expectation and role performed by lady supervisors the maximum gap was observed in the area of reporting followed by liaison and linkages and evaluation.
\end{abstract}

KEY WORDS : Role expectation, Role performance, Lady supervisor, ICDS

View Point Article : Kumari, Runi, Singh, Meera and Paswan, A.K. (2017). Role expectation and role performance of lady supervisors under ICDS. Internat. J. Home Sci. Extn. \& Comm. Manage., 4 (1): 53-56. DOI : 10.15740/HAS/IJHSECM/4.1/5356.

Article History : Received : 06.11.2016; Revised : 10.12.2016; Accepted : 26.12.2016

\footnotetext{
* Author for correspondence (Email : runihsc14@gmail.com)
} 